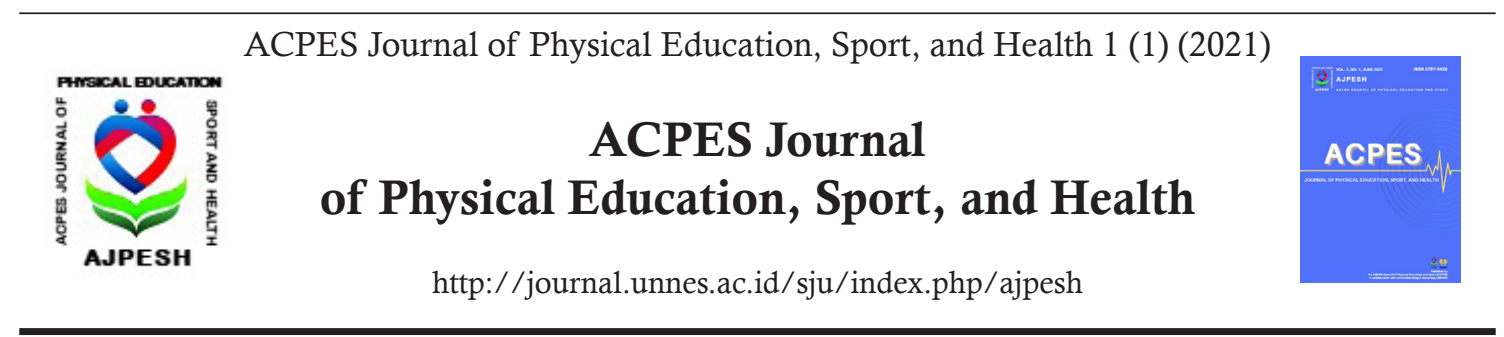

\title{
Impact of Technology Enhanced Video Feedback and Peer Evalua- tion on Gymnastic Performance in a Middle Years Program (MYP) International Baccalaureate Physical Education Class
}

\author{
Andrew Hutcheon ${ }^{1,2 \bowtie}$ \\ ${ }^{1}$ Institute of Technical Education, Singapore \\ ${ }^{2}$ University of Sunderland, United Kingdom \\ DOI: https://doi.org/10.15294/ajpesh.v1i1.46294
}

\section{Article Info \\ Article History \\ Submitted 8 January 2021 \\ Revised 24 April 2021 \\ Accepted 4 June 2021}

Keywords

Video Analysis; peer-topeer scaffolding; MYP

Physical Education.

\begin{abstract}
An analysis of the impact of technology-enhanced video feedback and peer evaluation on gymnastic performance in a MYP IB Physical Education class. A 5-step inquiry action research framework was employed; following the triangulation approach, both qualitative and quantitative data was collected to substantiate the findings. This study evidenced that peer feedback enhanced gymnastics performance, and that peer feedback when coupled with video analysis, further saw bolstered improvements. Suggesting both methods have a place in physical education, if conducted in the right manner. Adept use of appropriate technological tools would foster heightened intrinsic motivation and differentiated learning engagement.
\end{abstract}

\section{INTRODUCTION}

The research project was implemented in an international school Gymnastics class for grade 6 students who take part in the MYP IB program. Twenty-One students from one class took part in this study. For 2 weeks (4 lessons) the students performed basic rolling actions (log roll, tucked roll, forward roll, backwards roll) with the use of peer feedback to improve Gymnastics performance, and for the next 2 weeks (4 lessons) students completed travelling actions (cartwheel, round off, walk overs) with the use of video analysis (tablet/iPhone) to improve Gymnastics performance.

It was noted that much of the observable assessment criteria in MYP IB Physical education, within the Physical and Health Education subject group, is swayed

$\bowtie$ Correspondence Author:

10 Simei Avenue Singapore 486047

e-ISSN 2797-0426

E-mail: andrew_john_hutcheon@ite.edu.sg 
towards the Criteria D component (where students are expected to reflect on their performance and the performance of others), and the Criteria C component (where the students apply and perform a specific task) during practical sessions. However, often when students gave peer feedback, the advice was frequently construed as critical, non-constructive and lacked focus which was seen to be detrimental to the students' performance and self-esteem in Physical and Health Education, within the target demoFigureic.

The introduction of video analysis as a highly effective method of evaluating performance and tool to foster heightened awareness of error identification during specific gymnastic routines (Napolitano, 2016; Topping, 2000), is crucial due to the complexity and speed of movement in Gymnastics. Literature supports technology in the classroom as an effective method of instruction that improves students learning and educational outcomes (Devlin, 2013). Students have also found that peer feedback given in the right manner will improve student's motivation and motor performance (Harris, 2009), however some studies have also found that peer evaluation is not a great tool for performance improvement.

Ormond and Merry (1996) cited in Li et al. (2010) found that students had reservations regarding the value of the students marks and Li et al., Steckelberg \& Srinivasan (in press) cited in Li et al. (2010) stated that marked peer assessment is a beneficial exercise but feedback should be more constructive and detailed. This study tests the hypothesis that video technology in the classroom, allowed students to critically reflect on their own performance and the performance of peers, so students could perform to the best of their ability in the Gymnastic module.

If video analysis could be found to give students more detailed and constructive feedback, and therefore lead to performance improvement, this could be more widely used throughout the Physical and Health Education curriculum. This study was designed to address the following questions: 1 . What were the student's attitudes towards using peer feedback and peer feedback using video analysis in a MYP Gymnastic module? 2. What impact did peer feedback and peer feedback using video analysis have on Gymnastics performance?

\section{METHOD}

The following 5-step inquiry action research framework was employed. 1) Identify the problem 2) collection and organization of data 3) interpretation of data 4) action based on data 5) reflection (Mills, 2010). Following the triangulation approach, both qualitative and quantitative data was collected to substantiate the findings. Initially, the students participated in 4 x 60 minutes lesson over a 2-week period where they completed basic rolling actions.

The rolling actions the students completed were a log roll, tucked roll, forward roll, and backwards roll. Throughout the lessons, students were working in pairs and were expected to give each other peer feedback to improve their rolling actions. After the 4 Gymnastics lesson were completed, the students were required to fill up a questionnaire relating to how peer evaluation impacted their Gymnastic rolling performance (Appendix 1).

The second part of the study again looked at Gymnastics performance over a 2 -week period ( $4 \times 60$ minutes). This time students performed a variety of different 
traveling actions such as cartwheels, rounds off and walk overs. Peer evaluation was again used, but this time students used video analysis (iPad/iPhone) as an aid to peer evaluation. After the 4 Gymnastics lessons, students again filled in a questionnaire to get the responses from the students on how peer evaluation with the use of video analysis affected their Gymnastics performance (Appendix 2).

At the end of the first Gymnastics lesson, students were assessed with the use of the Criteria $C$ (applying and performing) gymnastics rubrics by their form teacher for students performing with peer feedback and peer feedback with the use of video analysis. Students were again assessed at the end of the 2 weeks ( 4 lessons) by their form teacher of peer evaluation of the rolling actions, and the peer evaluation with the use of video analysis for travelling movements again with the Criteria $C$ rubrics to determine any performance improvement with both peer evaluation and peer evaluation with video analysis (Appendix 3).

At the end of the 4 weeks ( 8 lessons) a focus group discussion was conducted with all twenty-one students to get their view on how beneficial peer feedback alone, and peer video with the use of video analysis impacted their gymnastics performance.

\section{RESULT AND DISCUSION}

After completing $4 \times 20$ minutes lesson of basic rolls (Figure 1.) - log roll, tucked roll, forward roll, backward roll, 12 students found peer feedback was a beneficial tool to improve Gymnastic performance compared to 9 students felt it was slightly beneficial and only one student felt that peer evaluation was no benefit to Gymnastics improvement.

After the 4 x 60 mins of practicing Gymnastics travelling actions (Figure 2.) cartwheels, rounds off and walk overs, 16 students found that video analysis as an aid for peer feedback improved their Gymnastics performance, compared to 5 students felt that video analysis was of slight benefit and 1 student felt video analysis was of no benefit to Gymnastics improvement.

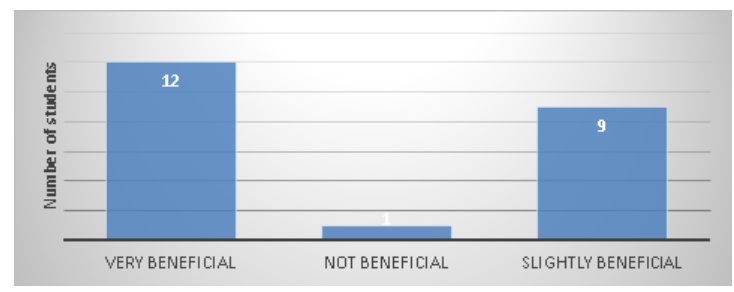

Figure 1. The impact of peer evaluation on Gymnastics improvement (Basic rolls).

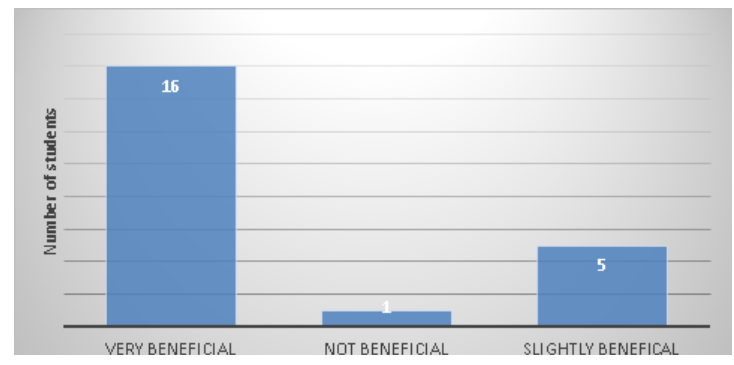

Figure 2. The impact of video analysis on Gymnastic performance (travelling actions). 


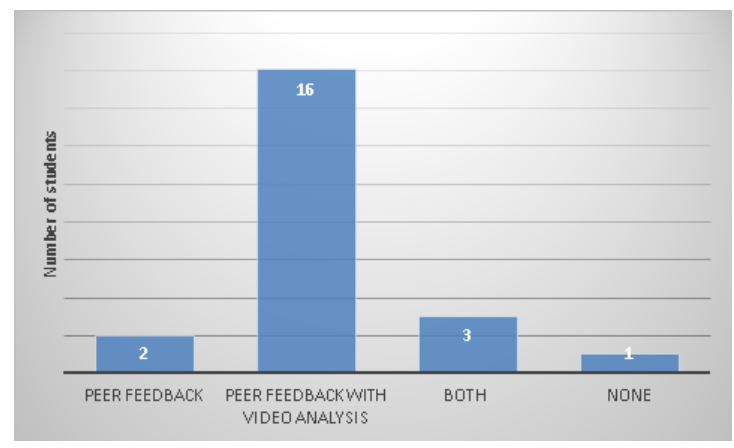

Figure 3. Preferred method of feedback for improving gymnastics performance.

On comparison of using peer evaluation only and peer evaluation with the aid of video analysis (Figure 3.), 16 students felt peer feedback with video analysis was the most effective method for improving Gymnastics performance, 2 students felt peer feedback only was the most effective method and 3 students believe that both peer feedback and peer feedback with video analysis was the most effective method.

18 students reported that peer feedback with the use of video analysis (Figure 4.), increased their confidence level in Gymnastics performance.

In relation to the impact peer evaluation alone had on confidence level in Gymnastics (Figure 5.), 14 students stated that it increased confidence, 3 mentioned their confidence level decreased and 4 students were not impacted by peer evaluation.

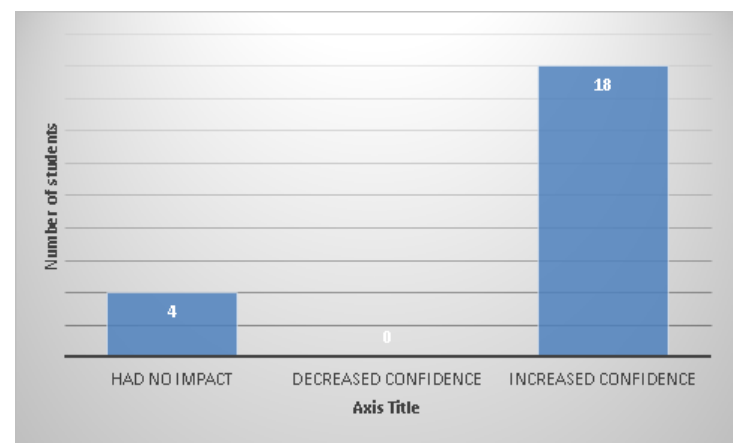

Figure 4. The impact peer feedback with video analysis has on confidence level in Gymnastics performance.

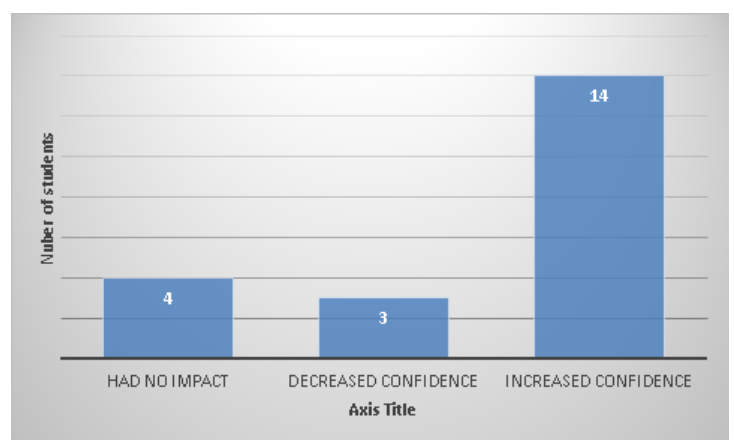

Figure 5. The impact peer evaluation has on confidence level in Gymnastics performance. 


\section{A. Hutcheon / AJPESH 1 (1) (2021)}

After reviewing the questionnaire with the regards to how peer feedback with the use of video analysis was beneficial to improving performance, students mentioned the following: 1 . That with the use of video analysis, the students were more aware of their mistakes; 2 . The feedback given by my peers was more focused and detailed compared to peer evaluation alone; 3 . The video could be slowed down and paused for greater awareness of my mistakes; 4 . Video analysis was preferred as with peer feedback alone I didn't really trust my partner's feedback as he has limited gymnastics knowledge; 5 . You can see exactly what is going wrong with video analysis. 6. I can reflect on my own performance and make improvements instead of just listening to my partner.

The students feedback by conducting peer feedback only to improve Gymnastics performance included: 1 . I was able to improve my rolling action as my partner was detailed with his feedback and I knew exactly how to improve in this area; 2.

It was difficult for me to understand the feedback given by my partner as I didn't know how my performance looked; 3. My partner mentioned that I performed perfectly but maybe she didn't want to hurt my feelings; 4. My partner gave me very specific feedback which helped me improve my performance. 5. The only feedback I got from my partner was I did it well which didn't really help me improve my skills; 6. My partner didn't show me the correct technique so I didn't understand his feedback; 7. My partner told me 10 areas for me to focus on and it didn't give me much motivation to try and improve because there was just too much to think about; 8 . My partner is very good at gymnastics so I believed her feedback and was able to use her knowledge to improve my Gymnastics technique.

Table 1. Students' performance scores with the use of peer feedback to improve rolling performance after lesson 1 and lesson 4.

\begin{tabular}{rrrr}
\hline & \multicolumn{3}{c}{ Students' performance with the use of peer evaluation } \\
\hline Name & Grade after lesson 1 & Grade after lesson 4 & Pre-Post difference \\
\hline Subject 1 & 3 & 5 & 2 \\
Subject 2 & 4 & 5 & 1 \\
Subject 3 & 6 & 6 & 0 \\
Subject 4 & 6 & 7 & 1 \\
Subject 5 & 3 & 4 & 1 \\
Subject 6 & 5 & 4 & -1 \\
Subject 7 & 1 & 3 & 2 \\
Subject 8 & 2 & 4 & 2 \\
Subject 9 & 1 & 4 & 3 \\
Subject 10 & 3 & 5 & 2 \\
Subject 11 & 7 & 6 & -1 \\
Subject 12 & 8 & 7 & -1 \\
Subject 13 & 3 & 5 & 2 \\
Subject 14 & 3 & 5 & 2 \\
Subject 15 & 4 & 5 & 1 \\
Subject 16 & 4 & 5 & 1
\end{tabular}




\begin{tabular}{lccc} 
Subject 17 & 5 & 6 & 1 \\
Subject 18 & 4 & 5 & 1 \\
Subject 19 & 2 & 3 & 1 \\
Subject 20 & 3 & 4 & 1 \\
Subject 21 & 3 & 4 & 1 \\
& & Total improvement & 22 \\
\hline
\end{tabular}

From Table 1, the total improvement scores for the 21 students studied was 22 points, all students improved their rolling performance apart from subject 6, 11 and 12 who had a decrease level in performance from lesson 1 compared to lesson 4 (performance graded with the MYP IB Criteria C rubric - Appendix 3).

From Table 2, all subjects improved their travelling gymnastics techniques from lesson 1 to lesson 4 with the use of video analysis as an aid to improve gymnastics performance. The total increase in score for the 21 students was 45 points (performance graded with the MYP IB Criteria C marking rubrics - Appendix 3).

After the completion of the 4 weeks of the gymnastics module, a focus group discussion was carried out to get the views of the class on the effectiveness of using peer feedback only or using video analysis as an aid to peer feedback to improve gymnastics performance. 19 out of the 21 students that attended the focus group discussion stated that using video analysis was most beneficial for improving gymnastics performance. Students mentioned the reason for this was the two-fold visual reference of techniques being critiqued with corresponding concise, corrective cues; instead of trying to internalise what the partner was trying to communicate, subjectly affected by their language and descriptive competence.

Common realisations denoted performance review mismatch upon analyzing the video playback. Peers may have limited knowledge of gymnastics and may not be able to articulate all coachable points, performer was however, able to watch the replay to compare performance, with many areas for improvements identified. All of the students in the focus group discussion mentioned that they had enjoyed using video analysis in the class and would like to use this more in the Physical Education curriculum (Jenkinson et al., 2014).

Table 2. Students performance scores with the use of video analysis as an aid to peer evaluation.

\begin{tabular}{cccc}
\hline \multicolumn{4}{c}{ Students' performance with the use of video analysis as an aid for peer evaluation } \\
\hline Name & Grade after lesson 1 & Grade after lesson 4 & Pre-Post difference \\
\hline Subject 1 & 3 & 6 & 3 \\
Subject 2 & 4 & 5 & 1 \\
Subject 3 & 5 & 7 & 2 \\
Subject 4 & 6 & 8 & 2 \\
Subject 5 & 4 & 6 & 2 \\
Subject 6 & 6 & 9 & 3 \\
Subject 7 & 1 & 3 & 2 \\
Subject 8 & 2 & 5 & 3 \\
Subject 9 & 1 & 4 & 3
\end{tabular}




\begin{tabular}{llll} 
Subject 10 & 3 & 6 & 3 \\
Subject 11 & 7 & 9 & 2 \\
Subject 12 & 7 & 9 & 2 \\
Subject 13 & 3 & 5 & 2 \\
Subject 14 & 3 & 5 & 2 \\
Subject 15 & 4 & 6 & 2 \\
Subject 16 & 4 & 6 & 2 \\
Subject 17 & 4 & 6 & 2 \\
Subject 18 & 4 & 5 & 1 \\
Subject 19 & 2 & 4 & 2 \\
Subject 20 & 3 & 5 & 2 \\
Subject 21 & 3 & 5 & 2 \\
& & Total improvement & 45 \\
\hline
\end{tabular}

\section{DATA ANALYSIS}

The majority of the students found peer evaluation and peer evaluation with the aid of video analysis to be a beneficial tool for improving gymnastics performance. This is in agreement with the literature which supports video analysis improving gymnastics performance (Napolitano, 2016; Ylenia et al., 2013) and leverage on peer evaluation improving students learning (Ayvazzo and Ward, 2009). When students were asked which method they preferred, 16 students stated that they preferred peer feedback with the use of video analysis, compared to 2 students preferring peer feedback only.

This high agreement of the students preferring video analysis as an aid for peer evaluation could be related to the students mentioning that with video analysis they are more aware of their mistakes, feedback was detailed, focused and the video could be slowed down so they could see exactly what they need to improve on. The feedback from the students was also in agreement with (Napolitano, 2016) who mentioned that when Gymnastics routines are performed quickly it is important to slow down the performance to identify errors for future improvement. The confidence level of the students was also compared with and without video analyses as an aid to improve gymnastics performance.

Both methods highlighted the majority of students increased their confidence level with both methods. 18 students stated that they increased their confidence with the use of video analysis compared to 14 students with the peer feedback only. What is interesting from the results on confidence level was that 3 students felt that they decreased their confidence level with peer evaluation compared to no students felt that video analysis had a detrimental effect to their confidence level.

One reason for the students decreasing their confidence level with peer feedback could be related to the type of feedback that the students receive from their peers. Some studies have shown that peer evaluation is not an effective tool as sometimes the feedback is not constructive and lacks details (Li, Steckelberg \& Srinivasan (in press) cited in Li et al. (2010)). However, if peer evaluation is conducted in the right 
way, confidence level would increase which was probably seen with the other 14 students.

This was supported by Harris (2009) who mentioned that peer evaluation conducted in the right manner would improve the student's motivation level. What wasn't looked into during this study was the relationship between confidence level and gymnastics improvement on given (assessor) or receiving (assesses) peer feedback. Some studies have shown that performance improvement is increased in the assessor as they are better at reflecting on their own performance by given feedback to others (Li et al. 2010).

Another area to look into with further research is the training students receive with regard to how they give peer feedback. Students may need to develop their communication techniques, be more aware of instructional techniques such as how they explain and demonstrate specific techniques, use scenarios to develop learning and test the students for peer feedback understanding at the end of the training so students don't have a negative impact on their peers when given feedback (Cervantes et al., 2013).

When we specifically look at performance improvement with peer evaluation only and with video analysis there was an overall performance improvement for both groups. For the 21 students that performed the rolling actions they had an improvement of 22 points and the improvement level for the 21 students that performed travelling actions with the use of video analysis there was an increase of 45 points in total score with the use of Criteria $C$ marking rubrics. Both sets of results showed that peer evaluation and video analysis are both effective ways of improving the students gymnastics performance.

However, there was a greater total performance improvement level with the use of video analysis. Only 3 students had shown that peer feedback actually decreases their gymnastics performance from lesson 1 to lesson 4 . These results could be again be associated with the negative feedback the students received could have had an impact on the students' self-esteem and overall performance level.

\section{CONCLUSION}

In order for results to be further improved with the use of video analysis in the Physical Education class, teachers need to be more aware and open to the uses of ICT in the classroom. Some studies have found that teachers of physical education found the introduction of ICT more of a burden than a relief, that the students are far more ICT competent than them, and that with the introduction of ICT will take away the movement time which is a contradiction to what Physical Education is all about (Kretschmann, 2010; Kretschmann, 2015).

The view of lack of activity with the use of ICT in the classroom is disputed by some studies which found that video analysis in a volleyball lesson made the students more active than without video analysis (Ayvazo \& Ward, 2009). This study evidenced that peer feedback enhanced gymnastics performance, and that peer feedback when coupled with video analysis, further saw bolstered improvements. Suggesting both methods have a place in physical education, if conducted in the right manner. This can be done if the students acquire the appropriate instructional techniques such as positive general, specific and corrective feedback skills (Cervantes et al., 2013). 
Peer feedback can also help the teacher as it is difficult for the educator to cater for all children in large classes (Ayvazo \& Ward, 2009) and differing ability of students can be catered for (Hodge et al cited in Cervantes et al., 2013). Video analysis as a method of improving gymnastics performance was very evident from this study and is supported by several studies in the Physical education literature (Napolitano, 2016, Ylenia et al., 2013, Ayvazo \& Ward, 2009). However, if the physical education staff seeks to leverage on technology to further stimulate their students, they will need to be specifically adept at appropriate types of technology and software application tools, for effective application in the session setting for further performance improvements.

Video analysis as an aid for improving Gymnastics performance has been seen to be an effective method of teaching, however, the use of video analysis can be further developed with staying up to date with current trends in the industry. Video analysis software applications such as Coach's Eye \& Dartfish video analysis, provide interactive drawing tool overlays where students can highlight specific learning points and can compare videos side by side for further analysis breakdown of performance in many sports (Hatten \& Christensen, 2008; Rutkowski et al., 2011).

Should teachers be able to engage the students with increasingly mobile technology adoption beyond the classroom, they will test the student's higher order thinking, as they will be able to apply what they have learnt in the classroom, analyze their own performance and the performance of their peers towards heightened intrinsic motivation and differentiated learning engagement.

\section{ACKNOWLEDGEMENT}

Much appreciation to the University of Sunderland, England, with special mention to the Sports Studies and Physical Education departments of the Institute of Technical Education, Singapore.

\section{REFERENCES}

Ayvazo, S. \& Ward, P. 2009. Effects of classwide peer tutoring on the performance of sixth grade students during a volleyball unit. Physical Educator, 66(1): 2.

Cervantes, C.M., Lieberman, L.J., Magnesio, B. \& Wood, J. 2013. Peer tutoring: Meeting the demands of inclusion in physical education today. Journal of Physical Education, Recreation \& Dance, 84(3): 43-48.

Devlin, T.J., Feldhaus, C.R. \& Bentrem, K.M. 2013. The evolving classroom: A study of traditional and technology-based instruction in a STEM classroom. Journal of Technology Education, 25(1): 34-54.

Harris, F. 2009. Visual Technology in Physical Education using Dartfish Video Analysis to Enhance Learning: An Overview of the Dartfish Project in New Brunswick. Physical \& Health Education Journal, 74(4): 24-25.

Hatten, T.L., \& Christensen, R. 2008. IAHPERD Endowment Fund Grant Summary: The Integration of Dartfish Video Analysis Software in the College Classroom. Illinois Journal for Health, Physical Education, Recreation and Dance, 
61: $55-57$

Jenkinson, K.A., Naughton, G. \& Benson, A.C. 2014. Peer-assisted learning in school physical education, sport and physical activity programmes: a systematic review. Physical Education and Sport Pedagogy, 19(3): 253-277.

Kretschmann, R. 2010. Physical Education 2.0. In Looking Toward the Future of Technology-Enhanced Education: Ubiquitous Learning and the Digital Native. Ebner, M. \& Schiefner, M. (Eds). IGI Global. https://www.igi-global.com/book/looking-toward-future-technology-enhanced/37243

Kretschmann, R., 2015. Physical Education Teachers' Subjective Theories about Integrating Information and Communication Technology (ICT) into Physical Education. The Turkish Online Journal of Educational Technology, 14(1): 68-96.

Li, L., Liu, X. \& Steckelberg, A.L. 2010. Assessor or assessee: How student learning improves by giving and receiving peer feedback. British Journal of Educational Technology, 41(3): 525-536.

Mills, G.E. 2010. Action Research: A guide for the teacher researcher. New York: Person Publishing.

Napolitano, S. 2016. The use of video analysis for self-assessment in aerobics. Journal of Physical Education and Sport, 16(4): 1207.

Rutkowski, D., Rutkowski, L., \& Sparks, J. 2011. Technologies Support for 21stCentury Teaching: An International Analysis. Journal of School Leadership 21(2): 190-215. https://journals.sagepub.com/doi/10.1177/105268461102100203

Topping, K.J., Smith, E.F., Swanson, I. \& Elliot, A. 2000. Formative peer assessment of academic writing between postgraduate students. Assessment \& evaluation in higher education, 25(2): 149-169.

Ylenia, G., Salvatore, N., Riccardo, I. \& Gaetano, R. 2013. Assessment of aerobic gymnastics by video analysis. Ovidius University Annals, Series Physical Education and Sport/Science, Movement and Health, 13(2): S205-S205. 


\section{APPENDIX}

\section{Appendix 1 - Peer Evaluation on Gymnastic Performance}

How beneficial was receiving peer feedback from your classmate on your gymnastic performance?

Very beneficial

Explain your answer to question 1.

- Not beneficial

- Slightly beneficial

Did the feedback you receive help improve your Gymnastic performance?

Yes -No

In relation to your answer to question 3. How did the feedback you received impact your Gymnastic performance?

What are some of the issues you faced when receiving peer feedback?

How did the peer feedback effect your confidence level in the Gymnastics module? Had no impact - Decreased my confidence - Increased my confidence Did you agree with the feedback given in the peer evaluation?

Yes - No

Was the assessor able to provide constructive suggestions for improvement?

Yes - No

What other type of feedback would be beneficial to improve Gymnastic performance?

In relation to your answer in Qn 9, why would this type of feedback be beneficial? 
Appendix 2 - Peer Evaluation on Gymnastic Performance via Video Analysis Which of the following was most beneficial to improve Gymnastic performance? Peer Feedback - Peer Feedback with Video Analysis - Both - None Can you expand on your answer to Qn 1?

How beneficial was receiving peer feedback via Video analysis from your classmate on your Gymnastic performance?

Very beneficial - Not beneficial

- Slightly beneficial

Did the feedback via Video analysis help improve your Gymnastic performance?

Yes - No

If you answered yes to Qn 4, why was Video analysis beneficial in improving Gymnastic performance?

How did peer evaluation via video analysis effect your confidence level in the gymnastic module?

Had no impact

- Decreased my confidence - Increased my confidence

Did you agree with the feedback given via video analysis?

Yes

- No

Was the assessor able to provide constructive suggestions for improvement?

Yes - No

Why do you think Video analysis is a good way to give feedback in the Gymnastic module?

Any other comments with regards to video analysis as a means for peer evaluation. 


\section{Appendix 3}

GRADE 6 GYMNASTICS RUBRIC

\section{Criteria C: Applying \& Performing}

At the end of year 1, students should be able to:

i. recall \& apply a range of skills and techniques

ii. recall \& apply a range of strategies and movement concepts

iii. recall \& apply information to perform effectively

\begin{tabular}{|c|c|c|}
\hline Level & Descriptor & Gymnastic Specific \\
\hline $\mathbf{0}$ & $\begin{array}{l}\text { The student does not reach a standard described by any } \\
\text { of the descriptors below. }\end{array}$ & The student was unable to reach the standard required. \\
\hline $1-2$ & $\begin{array}{l}\text { The student: } \\
\text { i. recalls limited skills and techniques } \\
\text { ii. recalls limited strategies and movement concepts } \\
\text { iii. recalls limited information to perform }\end{array}$ & $\begin{array}{l}\text { The student: } \\
\text { i. recalls limited skills and techniques such as travelling, rolling \& } \\
\text { balancing actions to create a short gymnastics sequence with a part- } \\
\text { ner. } \\
\text { ii. recalls limited strategies and movement concepts such as changes } \\
\text { in pathways and levels } \\
\text { iii. recalls limited information to perform such as focus \& clarity } \\
\text { of shape }\end{array}$ \\
\hline 3-4 & $\begin{array}{l}\text { The student: } \\
\text { i. recalls some skills and techniques } \\
\text { ii. recalls some strategies and movement concepts } \\
\text { iii. recalls some information to perform }\end{array}$ & $\begin{array}{l}\text { The student: } \\
\text { i. recalls some skills and techniques such as travelling, rolling \& bal- } \\
\text { ancing actions to create a short gymnastics sequence with a partner. } \\
\text { ii. recalls some strategies and movement concepts such as changes in } \\
\text { pathways, levels, directions and timing (cannon \& unison). } \\
\text { iii. recalls some information to perform such as focus, clarity of } \\
\text { shape, body tension \& extension }\end{array}$ \\
\hline 5-6 & $\begin{array}{l}\text { The student: } \\
\text { i. recalls and applies some skills and techniques } \\
\text { ii. recalls and applies some strategies and movement } \\
\text { concepts } \\
\text { iii. recalls and applies some information to perform ef- } \\
\text { fectively }\end{array}$ & $\begin{array}{l}\text { The student: } \\
\text { i. recalls and applies some skills and techniques such as travelling, } \\
\text { rolling \& balancing actions to create a short gymnastics sequence } \\
\text { with a partner. } \\
\text { ii. recalls and applies some strategies and movement concepts such } \\
\text { as changes in pathways, levels, directions, timing (cannon \& uni- } \\
\text { son), speeds and different relationships with their partner (over, un- } \\
\text { der, on, around, etc) with flow. } \\
\text { iii. recalls and applies some information to perform such as focus, } \\
\text { clarity of shape, body tension \& extension and control }\end{array}$ \\
\hline 7-8 & $\begin{array}{l}\text { The student: } \\
\text { i. recalls and applies a range of skills and techniques } \\
\text { ii. recalls and applies a range of strategies and move- } \\
\text { ment concepts } \\
\text { iii. recalls and applies information to perform effec- } \\
\text { tively }\end{array}$ & $\begin{array}{l}\text { The student: } \\
\text { i. recalls and applies a range skills and techniques such as travelling, } \\
\text { rolling \& balancing actions to create a short gymnastics sequence } \\
\text { with a partner. } \\
\text { ii. recalls and applies a range of strategies and movement concepts } \\
\text { such as changes in pathways, levels, directions, timing (cannon \& } \\
\text { unison), speeds and different relationships with their partner (over, } \\
\text { under, on, around, etc) with flow. They can also demonstrate con- } \\
\text { trolled moments of hold. } \\
\text { iii. recalls and applies information to perform such as focus, clar- } \\
\text { ity of shape, body tension \& extension, control \& originality ef- } \\
\text { fectively. }\end{array}$ \\
\hline Key Word & \multicolumn{2}{|l|}{ Definition } \\
\hline Recall & \multicolumn{2}{|l|}{ Remember or recognise from prior learning experiences } \\
\hline Apply & \multicolumn{2}{|c|}{ Use knowledge \& understanding in response to a given situation or real circumstance } \\
\hline
\end{tabular}

